\title{
Cooking Matters for Adults Improves Food Resource Management Skills and Self-confidence Among Low-Income Participants
}

\author{
Jennifer A. Pooler, $\mathrm{MPP}^{1, \dagger}$; Ruth E. Morgan, $\mathrm{MPH}^{2, \dagger}$; Karen Wong, $\mathrm{MHS}^{3}$; \\ Margaret K. Wilkin, $\mathrm{MPH}^{4}$; Jonathan L. Blitstein, $\mathrm{PhD}^{5}$
}

\begin{abstract}
Objective: Determine the impact of Cooking Matters for Adults (CM) on food resource management (FRM) skills and self-confidence 6 months after course completion.

Design: Quasi-experimental design with nonequivalent comparison group and 6-month follow-up.

Setting: Cooking Matters for Adults programs in CA, CO, ME, MA, MI, and OR.

Participants: Participants in CM attending classes in April to July, $2016(\mathrm{n}=332)$; comparison group $(\mathrm{n}=336)$.

Intervention: Cooking Matters for Adults educated low-income adults to shop for and prepare healthy meals economically using hands-on meal preparation, facilitated discussion, and an interactive grocery store tour. Classes met for 2 hours, once a week for 6 weeks.

Main Outcome Measure(s): Food resource management practices; FRM self-confidence (ie, in shopping for and preparing healthy foods on a budget); worrying that food might run out.

Analysis: Pearson's chi-square test and $t$ tests identified measures associated with outcomes of interest and between-group differences. Repeated-measures linear mixed models with fixed and random effects were used to examine differences in outcomes between participants in CM and nonequivalent comparison group and to estimate the treatment effect of the program at 3 and 6 months after course completion.

Results: Six months after course completion, CM participants demonstrated improvements in all outcome measures of interest: Use of FRM practices improved $(P=.002)$ as did FRM confidence $(P<.001)$. Participants also worried less that food would run out before they had money to buy more $(P=.03)$.

Conclusions and Implications: This study demonstrated a positive impact of including FRM skills and confidence building in a nutrition education program, the effects of which could be seen for 6 months after participation in the program. Equipping low-income families with FRM skills allowed them to access healthier foods even during times of hardship.
\end{abstract}

Key Words: nutrition education, food resource management, low-income population, cooking (J Nutr Educ Behav. 2017;49:545-553.)

Accepted April 19, 2017.

\footnotetext{
${ }^{1}$ IMPAQ International, LLC, Columbia, MD

${ }^{2}$ US Department of Agriculture, Food and Nutrition Service, Alexandria, VA

${ }^{3}$ Share Our Strength, Washington, DC

${ }^{4}$ Altarum Institute, Ann Arbor, MI

${ }^{5}$ RTI International, Research Triangle Park, NC

${ }^{\dagger} \mathrm{Ms}$ Pooler and Ms Morgan were affiliated with Altarum Institute at the time this study was completed.

Conflict of Interest Disclosure: The authors' conflict of interest disclosures can be found online with this article on www.jneb.org.

Address for correspondence: Jennifer A. Pooler, MPP, IMPAQ International, 10420 Little Patuxent Pkwy, Ste 300, Columbia, MD 21044; Phone: (207) 892-0389; E-mail: Jennifer. Pooler@outlook.com

(C2017 Society for Nutrition Education and Behavior. Published by Elsevier, Inc. All rights reserved.

http://dx.doi.org/10.1016/j.jneb.2017.04.008
}

\section{INTRODUCTION}

Poor dietary quality is a risk factor for chronic disease and the risk is significantly greater among low-income families. High-quality diets that include a high proportion of fruits, vegetables, and lean proteins have been linked to lower risk of morbidity and all-cause mortality ${ }^{1,2}$ whereas poorquality diets that include a high proportion of nutrient-poor, calorie-dense foods have been associated with higher risk of obesity. ${ }^{3}$ This is a serious public health concern because research consistently shows an economic gradient in dietary quality. Higher socioeconomic 
status is correlated with better adherence to the Dietary Guidelines for Americans ${ }^{4}$ including increased consumption of fiber, fruits, and vegetables; and lower consumption of saturated fat and cholesterol. $^{5,6}$ In general, lower-income families underconsume fruits and vegetables, whole grains, and lean proteins, and overconsume processed meats, sugar-sweetened beverages, and energy-dense foods compared with middle- or high-income families. ${ }^{7}$

The cost of food is an important factor in the selection and purchase of foods by low-income households. ${ }^{8}$ Studies show that less energy-dense and more nutrient-dense foods (eg, fruits and vegetables) cost more than energy-dense foods (eg, those with added sugars and fats), which makes purchasing and consuming a healthy diet particularly challenging for lowincome populations. ${ }^{9-11}$ Among a small sample of low-income rural adults, Peterson et $\mathrm{al}^{12}$ found that cost, taste, and appearance of food were more important factors in food selection than were nutrient content or health. Wiig and Smith $^{13}$ found that low-income women reported wanting more fresh fruits and vegetables and healthier foods overall, but limited budgets prevented them from purchasing these foods. These authors concluded that enhanced food resource management (FRM) skills, nutrition knowledge, and meal preparation strategies could support low-income women in achieving a healthier diet for their families.

Food resource management practices include a set of techniques that promote selection of healthy foods and cost-effective shopping. These practices can improve the quality of the shopping basket for low-income families by helping shoppers purchase healthy foods while stretching food dollars. To purchase adequate amounts of food for their families, lowincome individuals may need to rely on a variety of FRM strategies such as shopping sales, looking for specials, comparison shopping among grocery stores, planning meals ahead of time, and buying bulk items. ${ }^{5,12,14}$ Martin et $\mathrm{al}^{15}$ found that self-efficacy in managing food resources (eg, confidence in being able to plan meals ahead of time, making a shopping list before going to the store, and making lowcost meals) was strongly associated with food security among food pantry clients. In an evaluation of Plan, Shop, Save, and Cook, Kaiser et $\mathrm{al}^{16}$ found that FRM skills gained through the program significantly improved Supplemental Nutrition Assistance Program (SNAP) participants' food security status at 1 month postintervention. The authors noted that nutrition education interventions should incorporate a focus on FRM practices to ensure that low-income families maximize their resources and are able to make their food money last all month.

Studies of nutrition education programs for low-income adults examined FRM practices as a program outcome, because it is a key component of the Expanded Food and Nutrition Education Program (EFNEP) and is often found in SNAP-Education (SNAP-Ed) activities. For example, Brite-Lane et $\mathrm{al}^{17}$ found that Arkansas EFNEP participants saw improvements in FRM practices, including planning meals ahead of time and shopping with a grocery list. Auld et $\mathrm{al}^{18}$ saw similar results for participants in the Eating Smart-Being Active program. Although the results of these studies were promising, they were conducted over a short time frame ${ }^{16,19}$ or did not use a comparison group to validate improvements in behaviors. ${ }^{17,18}$

Share Our Strength developed the Cooking Matters for Adults (Cooking Matters) nutrition education program with the goal of empowering low-income families with knowledge and skills that would allow them to shop for and cook healthy meals on a budget. The Cooking Matters curriculum provides participants with a mixture of nutrition knowledge, food preparation skills, and FRM skills that would enable them to shop for, prepare, and maintain a healthier diet within their limited resources. Based on Social Cognitive Theory, Cooking Matters aims to improve cooking and FRM skills through demonstrations and hands-on practice; in turn, these activities increase the likelihood that participants would prepare meals at home and better afford healthy foods. Building self-efficacy among participants is important in encouraging the uptake and maintenance of behaviors and skills learned during the course.

In 2014, the Cooking Matters Impact Evaluation was undertaken using a quasi-experimental design to examine each of the key aspects of the curriculum, because they all had an important role in empowering low-income adults to eat more healthfully. One of the stated goals of Cooking Matters was to "increase knowledge of techniques that promote selection of healthy foods and cost-effective shopping so that these techniques can be applied in the participant's home to support healthy eating and resource management." This article presents the results of a quasiexperimental study that looked at the influence of Cooking Matters participation on FRM skills and self-confidence in managing food resources up to 6 months after program completion. This study was part of a national evaluation aimed to assess the impact of the Cooking Matters program, which included other measures related to the purpose of the program that are not reported here.

\section{METHODS \\ Overview of Cooking Matters}

Cooking Matters was designed for lowincome adults and uses hands-on meal preparation, facilitated discussion, and an interactive grocery store tour to teach participants how to shop economically and prepare healthy meals. Cooking Matters participants meet for 6 weeks, once each week for 2 hours, to learn basic cooking skills and nutrition concepts, and to prepare and share a meal together under the guidance of a nutrition and culinary educator. Topics covered include, but are not limited to, selecting and preparing fruits and vegetables of all forms, making and shopping with a list, using the same ingredients in more than 1 recipe, and using the nutrition facts panel and unit price labels. The course materials and curriculum are available in Spanish and English. Cooking Matters also provides take-home groceries and educational tools such as recipes and materials, to assist families in stretching food budgets and preparing healthy meals at home. These efforts are intended to reinforce the skills and lessons learned in class.

Cooking Matters courses are conducted in 46 states and the District of Columbia and are organized by hundreds of program partners, such as hunger and health service organizations, SNAP-Ed grantees, and local Share Our Strength offices that operate on the city, regional, or statewide level. Program partners collaborate with local organizations in their service area to act 
as partners in recruiting eligible participants and hosting programming. Program outcomes are captured through an established evaluation system of pre- and post-course surveys administered locally and then sent to Share Our Strength for analysis.

\section{Study Design and Data Collection}

The Cooking Matters impact evaluation used a quasi-experimental design to examine intermediate and long-term outcomes at 3- and 6-month followup. The study and all materials were approved by an external institutional review board at Social Solutions International, LLC. The study team sought partner agencies to participate in the study that (1) would conduct a large enough number of classes to meet the study recruitment goals, and (2) could provide course schedules well in advance to facilitate dissemination and coordination of study materials. Cooking Matters partner agencies in 6 states (CA, CO, ME, MA, MI, and OR) agreed to participate in the study. Designated points of contact at each partner agency coordinated with the study team regarding logistics and training for course coordinators to administer the study materials. The project director trained course coordinators via webinar to provide study information to participants and administer the signed informed consent before the pen-and-paper survey. The Web-based training was made available to course coordinators who could not attend scheduled trainings, and their supervisors.

At the start of the first class, the course coordinators introduced the Cooking Matters impact evaluation to all attendees by reading the prepared study description in English and/or Spanish, depending on the preferred language of participants. Course coordinators handed out the informed consent and survey materials and reviewed the information included in the form, and were available to answer questions about the study. Participants were told that their decision to participate in the study would not affect participation in the Cooking Matters course and that they could stop participating at any time. All participants were given time to review the informed consent; those who chose to participate were instructed to sign the form and to complete and tear off a contact card attached to the survey. The contact card contained a unique identifier and space to provide the participants' name, mailing address, and e-mail address. Participants passed the informed consent documents and contact cards to the course coordinator, who put them in an envelope and sealed it. Completed surveys (containing the same unique identifier as the contact card) were placed in a separate envelope. Course coordinators were given self-addressed envelopes to send materials back to the study team.

Upon receipt of the study materials, participant information was recorded into an Access database to facilitate 3and 6-month follow-up; survey responses were entered into an Excel (version 14.0; Microsoft Corporation, Redmond, WA) spreadsheet. All original copies of signed informed consent, contact cards, and survey responses were kept in a locked filing cabinet during the study period, after which they were shredded. Electronic and original participant information was kept separate from survey responses at all times and only study team members who were required to use the information had access to the files.

Although there were no set criteria for community members to participate in the course, adults participating in Cooking Matters in 6 states between late April and late July, 2014 and who attended classes taught in English or Spanish were invited to participate in the study. Participants in courses meant for adults with disabilities and those enrolled in courses taught in languages other than English and Spanish were excluded from the study. Course participants were given the option to receive materials on the study background, informed consent, and surveys in English or Spanish regardless of the language in which the course was taught. The baseline survey was administered at the start of the first class, and an immediate post-survey was administered at the end of the last class. Surveys at 3- and 6-month follow-up were conducted by mail and Web, and intervention participants were given a $\$ 5$ and $\$ 10$ gift card incentive, respectively, for completing the 2 follow-up surveys.

Because participation in Cooking Matters was voluntary, participants could not be assigned randomly to study conditions. Accordingly, a comparison group was recruited to participate in the study using an intercept recruitment approach at locations serving lowincome populations. Shadish et $\mathrm{al}^{20}$ noted that the comparison group design with preintervention and postintervention is one of the strongest alternatives to a randomized experimental design. To increase the likelihood of recruiting a population similar in demographics to those participating in Cooking Matters, the study team mapped the locations of Cooking Matters classes and identified agencies or organizations in the same or similar ZIP codes, including SNAP agencies, Special Supplemental Nutrition Program for Women, Infants, and Children clinics, community centers and YMCAs, and food pantries. Field data collectors intercepted individuals in these locations upon entry or exit (determined in collaboration with agency personnel so that services were not affected) and screened potential study participants to ensure that they were aged $>18$ years and the primary cook or food shopper in the household, and had not previously taken Cooking Matters. Participants also had to be able to read and write in English or Spanish, because the surveys were administered via pen and paper to both intervention and comparison groups in these 2 languages. Eligible individuals were then asked to participate in the study, provided the informed consent and study information, and asked to complete the survey onsite for a \$5 cash incentive. The same procedures for keeping contact cards and surveys separate for the intervention group were followed for comparison group recruitment. Comparison group participants received $\$ 10$ and $\$ 15$ gift card incentives for completing the 3- and 6-month follow-up surveys, respectively, which were conducted by mail and Web.

\section{Dependent Variables}

The Cooking Matters survey included 5 items specific to participants' shopping behaviors in the context of FRM. Three questions were initially derived from the EFNEP Behavior Checklist Questionnaire (BCQ) and then tested and validated for Cooking Matters participants ${ }^{21}$; 2 were included from the previously validated 
Fruit and Vegetable Shopping Scale developed by Baranowski et al. ${ }^{22}$ The 5 survey items asked respondents, How often do you ...

- Plan meals ahead of time? $\left(\mathrm{BCQ}^{23}\right)$

- Use a grocery list when you go grocery shopping? (modified $\mathrm{BCQ}^{21}$ )

- Compare prices before you buy food? $\left(\mathrm{BCQ}^{23}\right)$

- Look in the refrigerator/pantry before you go shopping to see what you need? (Fruit and Vegetable Shopping Scale ${ }^{22}$ )

- Change your grocery list in the store to include foods that are on sale? (Fruit and Vegetable Shopping Scale $^{22}$ )

Responses to these questions ranged from 1 (never) to 5 (always). Responses were averaged to create an FRM practices scale variable indicating the frequency with which respondents engaged in behaviors to maximize food resources. Cronbach $\alpha=.73$ indicated acceptable internal consistency among these measures.

Another outcome of interest was participants' self-confidence in being able to buy healthy foods and manage food resources. Two items from the previously validated Cooking Matters survey ${ }^{21}$ were specific to buying affordable, healthy foods, and 2 items from the self-efficacy for food security scale (SEFSS) $^{24}$ addressed preparation of affordable meals and making food resources last: How confident are you that you can ...

- Buy healthy foods for your family on a budget?

- Choose the best-priced form of fruits and vegetables?

- Make your food money last all month? (SEFSS ${ }^{24}$ )

- Make low-cost meals? (SEFSS ${ }^{24}$ )

Responses for these items ranged from 1 (not at all confident) to 5 (very confident). Cronbach $\alpha=.85$ indicated strong internal consistency among these measures; therefore an overall scale variable was created. Responses to the 4 items were averaged to create an FRM confidence scale indicating the extent to which participants showed self-confidence in shopping, preparing foods, and managing food resources on a budget.

The final outcome of interest asked, How often do you worry that your food might run out before you get money to buy more? This item was modified from the US Department of Agriculture's US Household Food Security Survey Module ${ }^{25}$ and was validated with Cooking Matters participants by Smith et al. ${ }^{21}$ Responses ranged from 1 (never) to 5 (always).

\section{Independent Variables}

The primary independent variable was a dichotomous indicator representing whether an individual participated in the Cooking Matters program or was a member of the comparison group. Additional independent variables were created and used in the analyses to control for differences in intervention and comparison group demographic characteristics. Participant characteristics from the survey included race and ethnicity, age, sex, highest level of education, household income, and receipt of public assistance. Responses to race and ethnicity questions were used to create 3 dichotomous variables representing Hispanic ethnicity, white race, and black race. Participants' highest level of education was a 5-category ordinal variable ranging from less than a high school degree to completion of a 4-year college degree. Household income as a percentage of poverty was calculated by comparing participants' reported household income in the past year and total number of people in the household with the US Department of Health and Human Services poverty guidelines for $2014 .{ }^{26}$ Mid-values for categorical income ranges collected in the survey were used to calculate income as a percentage of poverty; this method is commonly applied in analyses of national datasets in which only categorical income values are recorded. Finally, receipt of public assistance was included as a dichotomous variable indicating whether the respondent was receiving any of the following types of public assistance at the time of each survey: SNAP; Special Supplemental Nutrition Program for Women, Infants, and Children; free or reduced school breakfast or lunch (for children in the home); Head Start; or food from a food pantry.

\section{Data Analysis}

Univariate descriptive statistics (eg, frequencies and means) described the sample demographics and outcome variables. Normality tests for skewness and kurtosis were conducted for outcomes of interest at 6 months in both groups separately and values were within an acceptable range $( \pm 1.5)$. Preliminary bivariate analyses (eg, $t$ tests and chisquare tests) determined which sample characteristics were associated with the outcomes of interest and tested between-group differences crosssectionally. Pearson chi-square test statistic assessed differences in dichotomous independent variables, and independentsample $t$ tests examined associations with continuous outcome variables and tested for between-group differences.

The researchers assessed influence of attrition on generalizability using a logistic regression model to identify the demographic characteristics of study participants who were more or less likely to be retained in the study 6 months afterward. The attrition analysis included all participants enrolled in the study at baseline. The dependent variable was a dichotomous variable indicating whether the respondent provided data 6 months after the course was completed. Independent variables included treatment group (Cooking Matters or comparison), age, gender, race and ethnicity, poverty status, receipt of public assistance at baseline, highest level of education, and English or Spanish survey completion.

A series of statistical models assessed the impact of the Cooking Matters intervention by comparing baseline data with data collected at 3 and 6 months postintervention. Repeated-measures, linear mixed models with fixed and random effects examined differences between Cooking Matters and comparison group participants while accounting for demographic factors related to the outcomes and the correlation within subjects. These models accounted for the variation in baseline values between groups by treating the intercept as a random effect. The models included the baseline measure of the outcome variable and accounted for the correlation over time of repeated measures to estimate program impacts. For the repeated-measures models, dependent variables included the FRM practices scale, the FRM confidence scale, and worrying that food would run out. Primary independent variables included exposure to the Cooking 
Matters program (ie, treatment group), a variable indicating the data collection period (ie, time), and the interaction between exposure and time. Fixed-effect demographics variables in the models included age, gender, ethnicity, race, and poverty status. Receipt of public assistance was included as a timevarying covariate because receipt of assistance such as SNAP can change over time and may be strongly associated with an individual's ability to sustain changes related to the outcomes of interest. All analyses were conducted using SAS software (version 9.4, SAS System for Windows, SAS Institute, Inc, Cary, NC).

\section{RESULTS}

A total of 831 Cooking Matters program participants were enrolled in the study out of 1,056 program participants attending the classes at which recruitment occurred $(78.7 \%$ enrollment rate). On average, study participants completed more classes than did those who did not enroll in the study: 4.7 vs 3.9 out of 6 classes $(P<.001)$. To construct the comparison group, field data collectors intercepted 1,581 individuals at recruitment sites. Approximately $10 \%$ of potential participants $(\mathrm{n}=164)$ did not meet screening criteria (ie, aged $<18$ years, not the primary cook or shopper in the household, did not read and write English or Spanish) and 35.5\% of individuals refused $(n=361)$. In total, 856 adults were enrolled in the study comparison group $(60.4 \%$ enrollment rate).

Retention of both Cooking Matters and comparison group participants in the study after 6 months was suboptimal $(40.0 \%$ and $39.2 \%$, respectively), but expected for a predominantly low-income population. ${ }^{27,28}$ Table 1 shows the results of the attrition analysis. Study participants with less than a high school degree were 2.5 times more likely to be lost to follow-up (95\% confidence interval [CI], 1.43-4.37) than were those with a 4-year college degree. Study participants who were not receiving public assistance at baseline were $33 \%$ more likely to remain in the study (95\% CI, 0.47-0.95), and retention improved by about $2 \%$ for every year of a participant's age (95\% CI, 0.97-0.99).

Comparison group participants were more likely than Cooking Matters participants to be lost to follow-up at 6 months postintervention (adjusted odds ratio, 1.37; 95\% CI, 1.05-1.80). This was expected, and more subjects were recruited in the comparison group at baseline to produce almost equal-sized groups at the end of the study. Table 2 shows the demographic characteristics of intervention $(\mathrm{n}=332)$ and comparison $(\mathrm{n}=336)$ group participants retained in the study 6 months after course completion. The majority of study participants in both groups were female and non-Hispanic white, had incomes below $100 \%$ of the poverty level, received public assistance, and completed the survey in English. Comparison group participants were slightly younger than those in the intervention group on average, and had greater proportions of participants who were male $(P<.001)$ and Hispanic $(P=.03)$, and who had incomes below $100 \%$ of poverty $(P<.001)$.

Table 3 provides baseline responses to the 3 outcomes of interest for study participants retained in the study at 6 months. Cooking Matters participants scored lower on the FRM practices $(P<.05)$ and FRM confidence $(P=.001)$ scales, which indicated that they were less likely to use the 5 food shopping behaviors and less confident in the 4 confidence-related items than were comparison group participants. On the other hand, Cooking Matters participants were less worried that food might run out before they had the resources to buy more $(P=.003)$.

Results of the repeated-measures, linear mixed models are shown in Table 4, including adjusted means for baseline, 3- and 6-month outcomes, and the treatment effect of participating in the Cooking Matters program at 3 and 6 months postintervention. At both 3 and 6 months after course completion, Cooking Matters had a positive treatment effect for each of the outcomes measured. For instance, Cooking Matters participants' FRM practices scores increased from a mean of 3.83 at baseline to 4.02 at 3 and 6 months after course completion. The treatment effect of participating in Cooking Matters was +0.18 (SE,
$0.05)$ at 3 months $(P<.001)$, most of which was maintained at 6 months (treatment effect, +0.17; SE, 0.06; $P=.002)$. Participants also realized a treatment effect increase of +0.51 (SE, 0.11) after 6 months with regard to the FRM confidence scale. Finally, Cooking Matters participants were significantly less worried that food would run out before having money to buy more at 3 and 6 months postintervention, with treatment effects of -0.37 (SE, 0.10; $P<.001$ ) and -0.23 (SE, 0.10; $P=.02)$, respectively.

\section{DISCUSSION}

The Cooking Matters course is a handson program that aims to teach lowincome consumers how to maximize limited food dollars, encourages the purchase and preparation of healthier foods, and helps to overcome the perception that healthy foods are too expensive. ${ }^{8,12}$ Cooking Matters is offered in nearly every state in the nation and serves thousands of lowincome adults and families each year. A number of states also offer Cooking Matters as part of the SNAP-Ed curriculum, which makes evaluation of program outcomes particularly important for nutrition educators across the country. The SNAP-Ed Guiding Principles and Evaluation Framework documents recognize the importance of FRM practices in ensuring that "SNAP participants, or those who are potentially eligible, are stretching their food dollars and making healthful purchases." 29 The results of this study demonstrated that Cooking Matters can assist low-income adults in improving food shopping strategies and self-confidence in maximizing food dollars and that those improvements were maintained for at least 6 months after the course ended.

These findings are generally comparable to evaluations of other nutrition education programs that examined FRM practices $^{16-19}$ although the lack of a common measure across studies and differences in how estimates were reported generally makes direct comparisons challenging. For example, participants in the Eating Smart - Being Active intervention demonstrated increases in mean FRM scores (from 3.2 to 3.9; $P<$.001) that included planning meals 
Table 1. Attrition Analysis Comparing Odds of Not Completing 6-Mo Follow-up Between Intervention and Comparison Group Study Participants Using Baseline Characteristics

95\% Wald

\begin{tabular}{|c|c|c|c|c|}
\hline Characteristic & $\begin{array}{l}\text { Odds of Attrition } \\
\text { by 6-Mo Follow-up }\end{array}$ & $\begin{array}{r}\text { Confi } \\
\text { Lin }\end{array}$ & $\begin{array}{l}\text { ence } \\
\text { ts }\end{array}$ & $\boldsymbol{P}$ \\
\hline $\begin{array}{l}\text { Intervention group } \\
\text { Intervention } \\
\text { Comparison }\end{array}$ & $\begin{array}{c}\text { Reference } \\
1.37\end{array}$ & 1.05 & 1.80 & .02 \\
\hline $\begin{array}{l}\text { Race/ethnicity } \\
\text { White } \\
\text { Black/African American } \\
\text { Hispanic } \\
\text { Multiple/other race }\end{array}$ & $\begin{array}{c}\text { Reference } \\
1.53 \\
1.40 \\
1.54\end{array}$ & $\begin{array}{l}1.04 \\
0.96 \\
0.92\end{array}$ & $\begin{array}{l}2.25 \\
2.04 \\
2.57\end{array}$ & $\begin{array}{l}.39 \\
.80 \\
.49\end{array}$ \\
\hline $\begin{array}{l}\text { Language } \\
\text { English } \\
\text { Spanish }\end{array}$ & $\begin{array}{c}0.75 \\
\text { Reference }\end{array}$ & 0.46 & 1.24 & .27 \\
\hline $\begin{array}{l}\text { Education level } \\
\text { Less than high school degree } \\
\text { High school degree } \\
\text { Some college but did not graduate } \\
2-y \text { college degree } \\
4-y \text { college degree }\end{array}$ & $\begin{array}{c}2.50 \\
1.49 \\
1.18 \\
1.08 \\
\text { Reference }\end{array}$ & $\begin{array}{l}1.43 \\
0.96 \\
0.77 \\
0.65\end{array}$ & $\begin{array}{l}4.37 \\
2.31 \\
1.81 \\
1.79\end{array}$ & $\begin{array}{c}<.001 \\
.49 \\
.24 \\
.15\end{array}$ \\
\hline Age, y & 0.98 & 0.97 & 0.99 & $<.001$ \\
\hline $\begin{array}{l}\text { Poverty status } \\
\quad<100 \% \text { of poverty } \\
100 \% \text { to }<200 \% \text { of poverty } \\
\geq 200 \% \text { of poverty }\end{array}$ & $\begin{array}{l}\text { Reference } \\
0.72 \\
0.76\end{array}$ & $\begin{array}{l}0.52 \\
0.47\end{array}$ & $\begin{array}{l}1.01 \\
1.26\end{array}$ & $\begin{array}{l}.29 \\
.66\end{array}$ \\
\hline $\begin{array}{l}\text { Receipt of public assistance } \\
\text { Current receipt } \\
\text { Past or no receipt }\end{array}$ & $\begin{array}{l}\text { Reference } \\
0.67\end{array}$ & 0.47 & 0.95 & .03 \\
\hline
\end{tabular}

aHousehold received assistance from at least 1 of the following: Special Supplemental Nutrition Program for Women, Infants, and Children; Supplemental Nutrition Assistance Program; free or reduced school breakfast; free or reduced school lunch; free or reduced school supper; free summer meals; Head Start; or food pantry.

Note: Includes 1,687 respondents enrolled in the study at baseline.

ahead of time, comparing prices when shopping, not running out of food at the end of the month, and making a grocery list. ${ }^{18}$ Auld et al, $^{18}$ who also used a nonequivalent comparison (NEC) group design, reported improvements in FRM practices but lacked long-term follow-up to determine whether those improvements were maintained over time. Lohse et $\mathrm{al}^{19}$ found that About Eating participants improved the use of nutrition fact labels (mean increase of 3.1 to $3.3 ; P=.01$ ) after participating in the online nutrition education course but were no more likely to report comparing prices to save money after the course (mean of 4.1 pre and post).
An additional benefit to this study was the development and validation of an FRM practices scale that combined 3 items from the widely used EFNEP BCQ checklist with 2 items from the Fruit and Vegetable Shopping Practice Scale. $^{22}$ The FRM confidence scale was created for this study using 2 previous Cooking Matters questions and 2 items from the SEFSS. The scale combines items specific to purchasing healthy foods on a budget, making lowcost meals, and making food money last all month. These items showed acceptable internal consistency for Cooking Matters participants and may be used to assess other nutrition education curricula.
Although this study included a comparison group and a 6-month follow-up among a large, multi-state sample, its limitations should be noted. First, because Cooking Matters is a community-based, direct education program that relies on voluntary participation, a randomized design was not feasible. Accordingly, this evaluation employed a quasi-experimental design with an NEC group. The use of an NEC group left this study vulnerable to validity threats, including selection bias, which could have had a role in the observed results. In particular, Cooking Matters participants' willingness to make time and attend Cooking Matters classes suggests that they may have been more motivated than nonparticipants to improve FRM skills and learn how to manage a healthier diet. Despite this limitation, NEC is one of the strongest alternatives to a randomized experimental approach. ${ }^{20}$

Second, there were some potentially important differences between the comparison group and the Cooking Matters participants that could have influenced the findings. The intervention group was slightly older and more likely to be female, whereas the comparison group was $22 \%$ more likely to have incomes below poverty and more likely to report higher scores at baseline on FRM practices and selfconfidence. However, the comparison group showed no statistically significant changes in outcomes over time, which suggests that observed changes were not likely attributable to exogenous forces (ie, secular trends).

Third, the study could not account for external threats to validity, such as Cooking Matters participants seeking additional sources of education or information to supplement skills gained during the course. However, the comparison group was drawn from the same or similar communities in which Cooking Matters was offered, so external educational resources were likely available to both groups and thus accounted for in the NEC design. As such, the risk of this threat was low and unlikely to affect the overall findings 6 months after the course completion.

Finally, a few operational factors may limit the ability to generalize the study findings to other Cooking Matters participants. The study participants 
Table 2. Baseline Characteristics of Participants Completing 6-Mo Follow-up Survey, by Study Group

\begin{tabular}{|c|c|c|c|c|c|}
\hline \multirow[b]{2}{*}{ Characteristic } & \multicolumn{2}{|c|}{$\begin{array}{l}\text { Intervention } \\
(\mathbf{n}=332)\end{array}$} & \multicolumn{2}{|c|}{$\begin{array}{l}\text { Comparison } \\
(n=336)\end{array}$} & \multirow[b]{2}{*}{$\boldsymbol{P}^{\mathrm{a}}$} \\
\hline & $\mathbf{n}$ & $\%$ & $\mathbf{n}$ & $\%$ & \\
\hline $\begin{array}{l}\text { Sex } \\
\text { Female } \\
\text { Male }\end{array}$ & $\begin{array}{r}332 \\
299 \\
33\end{array}$ & $\begin{array}{r}90.1 \\
9.9\end{array}$ & $\begin{array}{r}336 \\
268 \\
68\end{array}$ & $\begin{array}{l}79.8 \\
20.2\end{array}$ & $<.001$ \\
\hline $\begin{array}{l}\text { Race/ethnicity } \\
\text { Non-Hispanic white } \\
\text { Non-Hispanic black } \\
\text { Hispanic } \\
\text { Other race/ethnicity }\end{array}$ & $\begin{array}{r}327 \\
179 \\
60 \\
61 \\
27\end{array}$ & $\begin{array}{r}54.7 \\
18.3 \\
18.7 \\
8.3\end{array}$ & $\begin{array}{r}333 \\
176 \\
48 \\
91 \\
18\end{array}$ & $\begin{array}{r}52.9 \\
14.4 \\
27.3 \\
5.4\end{array}$ & .03 \\
\hline $\begin{array}{l}\text { Completed surveys in: } \\
\text { English } \\
\text { Spanish }\end{array}$ & $\begin{array}{r}332 \\
306 \\
26\end{array}$ & $\begin{array}{r}92.2 \\
7.8\end{array}$ & $\begin{array}{r}336 \\
304 \\
32\end{array}$ & $\begin{array}{r}90.5 \\
9.5\end{array}$ & .44 \\
\hline $\begin{array}{l}\text { Education } \\
\text { Less than high school } \\
\text { High school or General } \\
\text { Equivalency Diploma } \\
\text { Some college } \\
\text { 2-y degree } \\
\text { 4-y degree }\end{array}$ & $\begin{array}{r}323 \\
31 \\
96 \\
\\
89 \\
36 \\
71\end{array}$ & $\begin{array}{r}9.6 \\
29.7 \\
\\
27.6 \\
11.2 \\
22.0\end{array}$ & $\begin{array}{r}328 \\
31 \\
108 \\
\\
92 \\
45 \\
52\end{array}$ & $\begin{array}{r}9.5 \\
32.9 \\
28.1 \\
13.7 \\
15.9\end{array}$ & .32 \\
\hline $\begin{array}{l}\text { Poverty status } \\
\quad<100 \% \text { of poverty } \\
100 \% \text { to }<200 \% \text { of poverty } \\
\geq 200 \% \text { of poverty }\end{array}$ & $\begin{array}{r}278 \\
143 \\
99 \\
36\end{array}$ & $\begin{array}{l}51.4 \\
35.6 \\
13.0\end{array}$ & $\begin{array}{r}301 \\
199 \\
61 \\
41\end{array}$ & $\begin{array}{l}66.1 \\
20.3 \\
13.6\end{array}$ & $<.001$ \\
\hline $\begin{array}{l}\text { Receipt of public assistance } \\
\text { Current receipt } \\
\text { Past or no receipt }\end{array}$ & $\begin{array}{l}332 \\
217 \\
115\end{array}$ & $\begin{array}{l}65.4 \\
34.6\end{array}$ & $\begin{array}{r}336 \\
237 \\
99\end{array}$ & $\begin{array}{l}70.5 \\
29.5\end{array}$ & .16 \\
\hline Age, y (mean \pm SD) & 50.6 & 16.4 & 43. & 14.1 & \\
\hline
\end{tabular}

${ }^{\text {a }} P$ is based on chi-square test for proportions and $t$ test for means; ${ }^{b}$ Household received public assistance from at least 1 of the following: Special Supplemental Nutrition Program for Women, Infants, and Children; Supplemental Nutrition Assistance Program; free or reduced school breakfast; free or reduced school lunch; free or reduced school supper; free summer meals; Head Start; or food pantry. Note: Includes 332 intervention and 336 comparison group participants who completed the 6-month follow-up.

were from 6 states with established programs that were willing to participate in the study. By recruiting partner organizations with a sizeable number of courses, the study included states with well-established programs. These states may have differed from other states in the way programs were administered. Whereas Cooking Matters curriculum, guidelines, and training aim to promote consistency across programs, course-level factors could have influenced the success of individuals in sustaining behavior change and self-efficacy. A recent study of SNAP-Ed programs found that experience in program delivery was influential in determining success: Programs with a longer operating history were more likely to demonstrate participant-level change. ${ }^{30}$ Because the study design included in-person recruitment of a comparison group in specific geographic locations, it was not logistically feasible to include $>6$ states. Loss to follow-up among Cooking Matters participants at 6 months postintervention also might have limited generalizability of the findings, because those who did not respond may have been unable to respond owing to circumstances that could also have influenced their ability to maintain positive changes at 6 months after course completion. In particular, participants without a high school degree were more likely to drop out of the study compared with those with more education.

Despite these limitations, the current study demonstrated the positive impact of including a focus on FRM skills and self-confidence in healthy food purchasing in nutrition education programs that target low-income audiences. The Cooking Matters program contributed to improved selfconfidence in healthy shopping practices and managing food resources. Further supporting the importance of this type of intervention, previous studies linked FRM skills development with increased self-sufficiency. ${ }^{16}$ Similarly, an evaluation of the Freshplace food pantry model found that every unit increase in FRM self-efficacy reduced very low food security by $56 \%$ among a population of food pantry clients. ${ }^{1}$

\section{IMPLICATIONS FOR RESEARCH AND PRACTICE}

Low-income families face greater financial hardships and greater risk for adverse health outcomes than do their higher-income counterparts. Equipping low-income families with FRM skills may allow them to access healthier foods even during times of hardship. Food resource management is an integral part of the Cooking Matters curriculum and the findings from this study validate the importance of FRM as a key skill that helps lowincome families shop and eat healthier on a budget. Nutrition education programs such as SNAP-Ed that are designed for low-income audiences may want to consider incorporating FRM skill-building into their curriculum. Ensuring low-income families have the opportunity to learn these skills can truly have a long-term impact on helping families stretch food dollars and eat healthier.

Food resource management is part of the SNAP-Ed evaluation framework and is 1 of the core indicators that direct education programs are encouraged to measure. ${ }^{29}$ The FRM practices and self-confidence scales developed for this study showed strong internal consistency and can provide a means 
Table 3. Baseline FRM Practices and Self-confidence Among Participants Completing 6-Mo Follow-up, by Study Group

\begin{tabular}{|c|c|c|c|}
\hline Outcome Measure & $\begin{array}{c}\text { Intervention }(n=332) \\
\text { Mean (SD) }\end{array}$ & $\begin{array}{c}\text { Comparison }(\mathbf{n}=336) \\
\text { Mean }(\mathrm{SD})\end{array}$ & $\boldsymbol{P}^{\mathrm{a}}$ \\
\hline $\begin{array}{l}\text { FRM Practices } \\
\text { Scale }^{\text {b }}\end{array}$ & $3.79(0.76)$ & $3.98(0.78)$ & .035 \\
\hline $\begin{array}{l}\text { FRM Confidence } \\
\text { Scale }^{C}\end{array}$ & $3.62(0.99)$ & $3.78(0.95)$ & .001 \\
\hline $\begin{array}{l}\text { Worry that food might } \\
\text { run out }^{d}\end{array}$ & $2.94(1.30)$ & $3.23(1.27)$ & .003 \\
\hline
\end{tabular}

FRM indicates food resource management.

${ }^{\mathrm{a}} P$ is based on $t$ test for means; ${ }^{\mathrm{b}}$ Based on a mean of 5 items; responses ranged from 1 (never) to 5 (always); 'Based on a mean of 4 items; responses ranged from 1 (not at all confident) to 5 (very confident); ${ }^{d}$ Responses ranged from 1 (never) to 5 (always); lower score is more favorable.

Note: Includes 332 intervention and 336 comparison group participants who completed the 6-month follow-up.

for common assessment of nutrition education programs incorporating FRM practices in their curriculum. Nutrition education administrators and researchers might consider validating these scales with their participants to measure the extent to which participants increase FRM practices and self-confidence as a result of their program. Because, to the authors' knowledge, this study was the first to use this FRM self-confidence scale, additional research could help to support the use of the instrument in practice.
Improving FRM practices and selfconfidence is intended to enable lowincome adults to stretch food dollars in times of hardship. Further research could focus on the extent to which improvements in FRM practices and self-confidence contribute directly to improved nutrition and healthy eating practices for low-income individuals. For instance, being able to estimate increases in fruit and vegetable consumption and other healthy eating behaviors resulting from an improvement of +0.18 in FRM practices and
+0.51 in FRM self-confidence, beyond other program effects, could be valuable to nutrition education planning and add to the literature. Although nutrition education interventions may not be able to address all of the barriers to healthful eating for low-income families, connecting improvements in FRM behaviors and self-efficacy with long-term improvements in healthy eating behaviors can help shape the focus and design of food practices and nutrition education.

\section{ACKNOWLEDGMENTS}

The information Ms Morgan provided was done in her personal capacity; the opinions expressed herein are the author's own and do not reflect the view of the US Department of Agriculture, the Food, Nutrition, and Consumer Services Agency, or the US Government.

The authors gratefully acknowledge that this research was made possible through funding from Walmart. They would also like to thank their education partners, who agreed to help recruit Cooking Matters participants for the study. Finally, they would like to thank the more than 1,600 individuals who agreed to participate in the evaluation and took time to complete the surveys.

Table 4. Effect of Participation in Cooking Matters at 3 and 6 Mo After Course Completion

\section{Intervention $(\mathbf{n}=\mathbf{2 7 8})$ \\ Least Squares Mean (SE)}

Comparison $(\mathbf{n}=301)$

\section{Least Squares} Mean (SE)

\begin{tabular}{|c|c|c|c|c|c|c|}
\hline \multirow{2}{*}{$\begin{array}{l}\text { Outcome } \\
\text { Measure }\end{array}$} & \multicolumn{3}{|c|}{ IVIean (DE) } & \multicolumn{3}{|c|}{ Iviean } \\
\hline & Baseline & 3 Mo & $6 \mathrm{Mo}$ & Baseline & 3 Mo & $6 M$ \\
\hline $\begin{array}{l}\text { FRM Practices } \\
\text { Scale }^{\mathrm{b}}\end{array}$ & $\begin{array}{c}3.83 \\
(0.05)\end{array}$ & $\begin{array}{c}4.02 \\
(0.05)\end{array}$ & $\begin{array}{c}4.02 \\
(0.05)\end{array}$ & $\begin{array}{c}3.96 \\
(0.04)\end{array}$ & $\begin{array}{c}3.97 \\
(0.04)\end{array}$ & \\
\hline $\begin{array}{l}\text { FRM Confidence } \\
\text { Scale }^{c}\end{array}$ & $\begin{array}{c}3.64 \\
(0.06)\end{array}$ & $\begin{array}{l}4.15 \\
(0.06)\end{array}$ & $\begin{array}{c}4.18 \\
(0.06)\end{array}$ & $\begin{array}{c}3.81 \\
(0.05)\end{array}$ & $\begin{array}{c}3.73 \\
(0.05)\end{array}$ & \\
\hline $\begin{array}{l}\text { Worry that food } \\
\text { might run out }\end{array}$ & $\begin{array}{l}3.00 \\
(0.08)\end{array}$ & $\begin{array}{c}2.69 \\
(0.08)\end{array}$ & $\begin{array}{c}2.64 \\
(0.08)\end{array}$ & $\begin{array}{c}3.25 \\
(0.08)\end{array}$ & $\begin{array}{l}3.32 \\
(0.08)\end{array}$ & \\
\hline
\end{tabular}

FRM indicates food resource management.

a The treatment effect is based on the group $\times$ time coefficient from a repeated-measures linear mixed model. Models included covariates representing participant characteristics, including sex, age, race, ethnicity, receipt of public assistance, and poverty status; 'based on a mean of 5 items; responses ranged from 1 (never) to 5 (always); ' Based on a mean of 4 items; responses ranged from 1 (not at all confident) to 5 (very confident); ${ }^{d}$ Responses ranged from 1 (never) to 5 (always); lower score is more favorable.

Note: Includes 278 intervention and 301 comparison group participants with complete data for all of the variables included in the regression models. 


\section{REFERENCES}

1. Wirt A, Collins CE. Diet qualitywhat is it and does it matter? Public Health Nutr. 2008;12:2473-2492.

2. Mccullough ML, Feskanich D, Stampfer MJ, et al. Diet quality and major chronic disease risk in men and women: moving toward improved dietary guidance. Am J Clin Nutr. 2002;76:1261-1271.

3. Wolongevicz DM, Zhu L, Pencina MJ, et al. Diet quality and obesity in women: the Framingham Nutrition Studies. Br J Nutr. 2010;103:1223-1229.

4. US Department of Agriculture, US Department of Health and Human Services. 2015-2020 Dietary Guidelines for Americans. http://health.gov/dietarygui delines/2015/guidelines/. Accessed May 13, 2017.

5. Beydoun MA, Wang Y. How do socioeconomic status, perceived economic barriers and nutritional benefits affect quality of dietary intake among US adults? Eur J Clin Nutr. 2008;62:303-313.

6. Kirkpatrick SI, Dodd KW, Reedy J, Krebs-Smith SM. Income and race/ ethnicity are associated with adherence to food-based dietary guidance among US adults and children. J Acad Nutr Diet. 2012;112:624-635.

7. Leung CW, Ding EL, Catalano PJ, Villamor E, Rimm EB, Willett WC. Dietary intake and dietary quality of low-income adults in the Supplemental Nutrition Assistance Program. Am J Clin Nutr. 2012;96:977-988.

8. Wiig Dammann K, Smith C. Factors affecting low-income women's food choices and the perceived impact of dietary intake and socioeconomic status on their health and weight. I Nutr Educ Behav. 2009;41:242-253.

9. Andrieu E, Darmon N, Drewnowski A. Low-cost diets: more energy, fewer nutrients. Eur J Clin Nutr. 2006;60:434-436.

10. Jetter KM, Cassady DL. The availability and cost of healthier food alternatives. Am J Prev Med. 2006;30:38-44.

11. Drewnowski A, Darmon N. Food choices and diet costs: an economic analysis. J Nutr. 2005;135:900-904.

12. Peterson SL, Dodd KM, Kyungmi K, Long Roth S. Food cost perceptions and food purchasing practices of uninsured, low-income, rural adults. J Hunger Environ Nutr. 2010;5:41-55.

13. Wiig K, Smith C. The art of grocery shopping on a food stamp budget: factors influencing the food choices of low-income women as they try to make ends meet. Public Health Nutr. 2008;12:1726-1734.

14. Darko J, Eggett DL, Richards R. Shopping behaviors of low-income families during a 1-month period of time. J Nutr Educ Behav. 2013;45:20-29.

15. Martin KS, Colantonio AG, Picho K, Boyle KE. Self-efficacy is associated with increased food security in novel food pantry program. SSM Popul Heal. 2016;2:62-67.

16. Kaiser L, Chaidez V, Algert S, et al. Food resource management education with SNAP participation improves food security. J Nutr Educ Behav. 2015; 47:374-378.

17. Brite-Lane A, Phelps J, Fuller S, Crook T, Hakkak R. Evaluating effectiveness of the Arkansas Expanded Food and Nutrition Education Program on changing food resource management and nutrition practice outcomes. FASEB J. 2015;29(1 suppl). http://www. fasebj.org/content/29/1_Supplement/911. 7.abstract.

18. Auld G, Baker S, Conway L, Dollahite J, Lambea MC, McGirr K. Outcome effectiveness of the widely adopted EFNEP curriculum Eating Smart, Being Active. J Nutr Educ Behav. 2015;47:19-27.

19. Lohse B, Belue R, Smith S, Wamboldt P, Cunningham-Sabo L. About Eating: an online program with evidence of increased food resource management skills for low-income women. J Nutr Educ Behav. 2015;47:265-272.

20. Shadish WR, Cook TD, Campbell DT. Experimental and Quasiexperimental Designs for Generalized Causal Inference. Boston, MA: Houghton-Mifflin; 2002.

21. Smith T, Chapman M, Pinard C, Yaroch A. Report of Cooking Matters for Adults: Cognitive Interviews, Psychometrics, and Pre-Post Analysis. Washington, DC: Share Our Strength; 2013.
22. Baranowski T, Missaghian M, Broadfoot A, et al. Fruit and vegetable shopping practices and social support scales: a validation. J Nutr Educ Behav. 2006;38:340-351.

23. US Department of Agriculture, $\mathrm{Na}-$ tional Institute of Food and Agriculture. EFNEP Behavior Checklist Review. Washington, DC: USDA; 2012. https:// nifa.usda.gov/sites/default/files/resource/ Behavior\%20Checklist\%20Review.pdf. Accessed May 22, 2017.

24. Colantonio AG. The Role of Self-Efficacy in Increasing Food Security Among Participants of a New Food Pantry Model in Hartford, CT [master's thesis]. Storrs, CT: University of Connecticut; 2013. http://digitalcommons.uconn.edu/gs_ theses/397. Accessed May 13, 2017.

25. US Department of Agriculture. US Household Food Security Survey Module. http://www.ers.usda.gov/topics/ food-nutrition-assistance/food-securityin-the-us/survey-tools.aspx\#household. Accessed September 9, 2016.

26. US Department of Health and Human Services. 2014 poverty guidelines. http://aspe.hhs.gov/poverty/14poverty. cfm. Accessed September 9, 2016.

27. Katz KS, El-Mohandes A, Johnson DM, Jarrett M, Rose A, Cober M. Retention of low income mothers in a parenting intervention study. J Community Health. 2001;26:203-218.

28. Nicholson LM, Schwirian PM, Groner JA. Recruitment and retention strategies in clinical studies with lowincome and minority populations: progress from 2004-2014. Contemp Clin Trials. 2015;45:34-40.

29. US Department of Agriculture Food and Nutrition Service. The Supplemental Nutrition Assistance Program Education (SNAPEd) Evaluation Framework: Nutrition, Physical Activity, and Obesity Prevention Indicators: Interpretive Guide to the SNAP-Ed Evaluation Framework. Washington, DC: US US Dept of Agriculture; 2016.

30. Williams PA, Cates SC, Blitstein JL, et al. Evaluating the impact of six Supplemental Nutrition Assistance Program Education interventions on children's at-home diets. Health Educ Behav. 2014;42:329-338. 


\section{CONFLICT OF INTEREST}

J. A. Pooler and R. E. Morgan were employed by Altarum Institute at the time of the study, which received funding from Share Our Strength to conduct the study. K. Wong is employed by Share Our Strength, which may be viewed as a potential conflict of interest because Share Our Strength founded and receives funding for the Cooking Matters program. The rest of the authors have not stated any conflicts of interest. 